NEW LITERARIA-

An International Journal of Interdisciplinary Studies in Humanities

Volume 3, No. 1, January-February, 2022, PP. 23-29

ISSN: 2582-7375

DOI: https://dx.doi.org/10.48189/nl.2022.v03i1.003

www.newliteraria.com

\title{
The Politics of Cultural Memory and Culinary Nationalism: Revisiting the Bangladesh Liberation War through Nadeem Zaman's In the Time of the Others
}

\section{Namrata Chowdhury}

\begin{abstract}
The Partition of the Indian subcontinent has been an area rife with scholarship and with the increasing turn towards memory studies, I propose to revisit the site of the borders from the field of gastronomy. The discursive practices employed in the mapping of memories through fictional landscapes and narratives by Nadeem Zaman, the Bangladeshi-American author will potentially open up the spatial coordinates to interpretation, with the focus on the eastern borders and specifically the Bangladesh Liberation War. The history of the nations will be revisited in an attempt to register the challenges of cultural opposition through the culinary registers. The culinary landscape authored by Nadeem Zaman addresses the gaps in the cultural memory of the nationalist movement at the heart of the Bangladesh Liberation War. In The Time of the Others by Nadeem Zaman would re-write the ideas nationalism, through alternate spaces, highlighting the 'culinary nationalism'. The paper also proposes to situate the culinary register with the broader discipline of memory studies and claim its space in what Alleida Assmann would call the 'archive', though 'trauma' studies have dominated the 'canon' of cultural memory of the Eastern borders of the Indian subcontinent and the Bangladesh Liberation War.
\end{abstract}

Keywords: Cultural Memory, Partition, Home, Culinary Citizenship, Gastro-nostalgia.

"We act as though history can be erased. Who can blame us? The cost of remembering can break our wilted spirits. But if we allow for erasure we tell ourselves that things can be forgotten, put in the dustbin. We tell ourselves it is possible to have acts without consequences". (Shamsie, 2002)

\section{Introduction}

-Kamila Shamsie, Kartography

The University of North Carolina at Chapel Hill organized a conference in 2017 on 'Culinary Nationalism in Asia' and brought together dialogues from nations and beyond territorial boundaries uniting scholars from cross cultural domains to focus on foodways. The idea of 'culinary nationalism' used in the paper was inspired first by the conference title and then by further scholarship. Cultural memory and the culinary register come together in this paper to inhabit those spaces in fiction which can be revisited to analyse their role in nationalism. On such an occasion where remembering and forgetting are wed into the politics of identity making and nation formation, the paper seeks to revisit the site of the Bangladesh Liberation War in fiction through Nadeem Zaman's In the Time of the Others to explore the idea of 'culinary 
nationalism'. Cultural theorist Aleida Assmann distinguishes between active and passive forms of remembering and forgetting as memory studies prepares grounds for revisiting those culinary sites that have "fallen out of the frames of attention". (Assmann, 2008, p. 98)

The Partition and the Western border of India had received greater critical attention in terms of the literary output than the Eastern borders and together, they became sites rife with a discussion on the "high politics of the break-up itself, the violence and major population movements, and the long shadows" which were cast upon three newly formed nation-states. (Schendel, 2001) (Harrington, 2016) The refugee and the displaced have subsequently been engaged in scholarly works as their experiences talk about "shared memory [that] could be a powerful mechanism through which the shelter-seekers acquired a specific identity" in 'Nostalgia of 'Desh', Memories of Partition'. (Raychaudhury, 2004) (Murshid, 2011) The state politics has made way for an exploration of the cultural dialogue that emerges in the culinary boundaries that divide and give the nation a distinct identity. These have been examined from the perspective of Bengali Hindu and Bengali Muslim food consumption practices in 'Culinary Boundaries and the Making of Bangladesh' (Mookherjee, 2008). What remains yet to be explored is the role of the culinary registers in the Bangladeshi nationalist practices, without a reference to the body of the displaced or the refugee or the wounded and the traumatized but that which participates in state politics vis-à-vis their eating.

Rituparna Roy in The Newsletter issued by the International Institute for Asian Studies in 2009 redirects the issue of the Western border grabbing the state attention while the crisis on the Eastern border for the "sense of urgency was totally lacking" and therefore assesses the role of Amitav Ghosh's The Hungry Tide in the light of the events its highlights and the voices it raises (Roy, 2009). But despite Roy's efforts to call to attention the Eastern borders, what remains elusive is that the experience is there on both the sides of the border drawn. And the Bangladesh side has devoted ample attention to state policies and politics (Ranjan, 2016) and the recent focus on 'creole nationalism' in Bangladesh, and the role of language and culture (Das, Bhattacharyya, \& Sarma, 2020). Recent efforts to unearth testimonies surrounding the Partition and the Bangladesh Liberation War has resulted in (Das C., 2017) which too takes up from the methodological standpoint of memory studies to elaborate on the war, the violence and the resistance. The events of 1971 in fiction and non-fiction have been analysed from the methodological framework of gender studies too (Parvin, 2015) (Nimni \& Khanom, 2016) leaving behind a gap when it comes to the politics of food consumption, eating, cooking, the people related to food and the culinary register altogether.

Nadeem Zaman's In the Time of the Others (2018) takes us through four such occasions where politics comes to the dinner table or the act of eating is itself politicized. It is these instances which warrant the scholar and the researcher to intervene and rescue from what Aleida Assmann calls "[t]he passive form of cultural forgetting" that "is related to nonintentional acts such as losing, hiding, dispersing, neglecting, abandoning, or leaving something behind" (Assmann, 2008, p. 98) that scholarship is guilty of. Scholarship has remarkably exercised the dietary politics on the bodies of the refugees and the displaced, but the dietary practices without these marginal figures seems to have escaped attention. Hunger, starvation, food provisioning in refugee camps have made their way to the political debate, but the dinner parties and the traditional cooks and the Madhu Canteen that Zaman imagines are yet to figure within the larger rhetoric of nationalist practices. What seems to have been the focus is the political resistance, the disciplining and regulating of bodies in the narrative, the officers and the uniforms, the soldiers and their checkpoints and the elaborate searches carried out in houses and compounds and people vanishing as the soldiers pushed and shoved the people in the villages to a corner. What seems to have been neglected in the course of the 
narrative are the gatherings of people who sit down to eat together and what they eat in the course of their meals.

\section{The Politics of the Dinner Table Conversations}

The narrative takes us through the Chowdhury villa, the party organized by the Judge Mubarak, Sam Truman's place and finally the young revolutionaries. The Chowdhury villa, which is home to Kamruzzaman and Aisha, the former retired from government service and the latter in a teaching position at the University, have an almost insulating layer of "jackfruit and mango trees" surrounding their house, but foreign and radical elements manage to penetrate the hedged borders. (Zaman, 2018, p. 5) Imtiaz and the group Samina, Ranjan, Khoka, Mitali, Rounak, all come to the villa, the former for the purpose of selling the house he inherited and the latter with the design of organizing their resistance, the smaller faction, the University faction of the Mukti Bahini, under the mentorship of their teacher, Aisha Chowdhury. Mokaddas, "the long-time cook" in the family feeds Imtiaz, but his rough hands from "[d]ecades of grinding spices, chopping vegetables, and scouring clean his kitchen after meals" (Zaman, 2018, p. 7) refuses to caress, feed and nurture the bodies of the revolutionaries. Mokaddas's resistance to let these radicals, the young university goers feed themselves from this household, from the "rich cooking" (Zaman, 2018, p. 9) which Imtiaz enjoys, and was once savoured by the sons of the family because he was always afraid, they will bring trouble and disrupt the order of the house, thereby resisting change.

This resistance towards the "Chhatra League" and the ones branded "pseudointellectuals and troublemakers" (Zaman, 2018, p. 19), "bad elements" (Zaman, 2018, p. 18) does not only come from the cook, Mokaddas but also from the head of the family, Kamruzzaman, but they proudly call the Chowdhury villa their home, and on Aisha is seen "a grin... a mother watching her children squabble and finding it endearing". (Zaman, 2018, p. 20) The Bhutto-Mujib talks at the Intercontinental, and the plans for the demonstrations all are eventually accepted by the older lot, who wanted to remain faithful to tradition, and mistakenly thought the Mukti Bahini would challenge traditions.

Judge Suleiman Mubarak's home too has an outer layer of groves, “enclosed by lemon and banana trees" (Zaman, 2018, p. 35), but the Judge invites a party to penetrate the property. There is however, a stark difference between the Chowdhury home and the Mubarak home, as in the former, guests are welcome by the hosts themselves, but in the latter "[a] uniformed guard, flanked by two armed soldiers, asked the names of guests as they arrived and crosschecked them against a list on a clipboard one of the soldiers held" (Zaman, 2018, p. 29). The occasion for which the Judge has thrown a party "was the arrival of a new army officer and his wife" (Zaman, 2018, p. 29) and everyone around the coffee table or the dinner table later are identified by their rank, their uniform, their place in the country's official service. Imtiaz notes that "most of the conversation during the meal" led by Judge Mubarak "appeared increasingly and deliberately controlled" and elsewhere the "army officers held muted conversations with each other". (Zaman, 2018, p. 37)

It is more than a dinner party. Captain Fazal Shaukat and Umbreen, General Rao Farman, the American woman Helen, Walt, Kamruzzaman and Aisha, Imtiaz have their places set on the table," [a]t the long dinner table, half of them were army officers in uniform, all seated on one side, the same as the Shaukats" (Zaman, 2018, p. 36) and their roles, political, dictated and orchestrated by their host, the Judge. The presence of Helen and Walt in the state of affairs adds gravity, as Helen insists "Walt is a military history buff", and the subject "he majored" in and "the only student that knew where Pakistan was and what was happening here". (Zaman, 2018, p. 32) This was an occasion unlike the homely touch and caregiving of 
Mokaddas and Aisha in the Chowdhury villa, where the party saw guests flowing in for "cocktail" and some remaining for the "dinner". (Zaman, 2018, p. 36) There was talk of the "martial law" and the "machine guns and checkpoints" and clearly sides were taken as is evident in Imtiaz's observation of the group gathered.

'They' signified the army. Each time it was alluded to, Imtiaz glanced at the party. It did appear as though the uniforms outnumbered the civilians, and a certain level of inequity was at work in the way the two groups were socializing. The uniforms were roaming freely, drinking like Prohibition-era regulars at a speakeasy, growing louder by the minute. Perhaps that was it, nothing more, Imtiaz thought. Too much liquor. And, yes, power, too, for many of the uniforms. It was, in the end, a party; power indeed to those that were enjoying it to their heart's desires. (Zaman, 2018, p. 33)

The uniformed servers with their plate of food are unable to soothe the tension that erupts as Aisha responds to the army officers and what follows is an "exodus of guests" post dinner which leaves only a handful of people with the Judge to enjoy the "coffee and tea" and "carafe of brandy" that the servers had placed in front of them. (Zaman, 2018, p. 41) The personal becomes political, as the dinner party, the uniformed guests, and the discussion all bring the state of affairs to the dinner table. The after-dinner conversation too had the mention of General Tikka Khan "Butcher of Baluchistan" which upset Kamruzzaman, and was possibly the evening that led him to soften towards the young revolutionaries who kept visiting Aisha. The food value is lost, eating becomes a mere social exercise that is regimented and regulated like the officers themselves and mirrors the spatial siege of the city by the martial law.

The dinner table and the conversation around it was the focus of the first section, but this section decodes the meaning of the food that is served on two separate occasions. The dishes cooked, the recipes perfected, elsewhere the staple grain all take us through the cultural landscape of the Bangladesh Liberation War. Cultural memory has been exploited to its very best by Zaman who takes us through different households, through the war-torn Bangladesh. While it is true that not all parts of Bangladesh, all corners, and every family suffered the same because of the war, fiction attempts to rescue from oblivion things forgotten at the very time that it essentializes the citizens with the body politic in a singular identity. Aleida Assmann talks about the "passive" form of cultural forgetting revealing: "What is lost but not materially destroyed may be discovered by accident at a later time in attics and other obscure depots, or eventually be dug up again by more systematic archaeological search". (Assmann, 2008, p. 98) As a scholar who is reading the sites of the Borders and the Bangladesh Liberation War in fiction, the culinary register undoubtedly bridges the gap and eating becomes a political act, and the dinner table doubles as the secretariat enclaves preparing for a political dialogue.

\section{The 'heritage' speak: Delicacies and the Delectable}

The dinner table in this section will be revealed to betray the fact that eating is political. The Americans as Helen herself had declared, in the dinner party at Judge Mubarak's residence, are people "who can't get our shit together... and then we fly around all over the world dropping our values on everyone else". (Zaman, 2018, p. 42) Sam Truman, the "official of the U.S. consulate" (Zaman, 2018, p. 181) on one occasion has guests at his place, not to be referred to as 'home', and invites Helen, Walter and Imtiaz to join him for lunch. The table set, Imtiaz and Helen walk in to witness a royal spread as Sam Truman had "auditioned" suitable candidates for the position of his personal cook and found the suitable one among the six in the "one of many khansamas to the Nawab family of Dhaka". (Zaman, 2018, p. 184) The "sun-leathered skin" (Zaman, 2018, p. 184) of the cook is a replica of "the loose skin on the old cook's 
[Mokaddas'] chin" (Zaman, 2018, p. 23) and yet the former remains nameless and the latter shines in all his distinctiveness.

The strategy that characterizes Sam Truman's cook and Mokaddas from the Chowdhury villa is reversed in the next section as the food cooked by the former gets greater mention than that by the latter. When Mokaddas Kaka has no one to feed his "rich cooking" to (Zaman, 2018, p. 9) the royal cook maintains his "age old protocol" to receive the feedback from his guests and curtsy "at the praise his work received". (Zaman, 2018, p. 184) This was no table set to feed the master and his handful of guests, but rather a spread for "very special occasions, weddings, Eid, formal dinners" and there was not one dish but a "range of dishes" placed in front of them. (Zaman, 2018, p. 184)

On an ordinary afternoon, for lunch, he [Sam Truman] was presented here with everything from Nargisi kofta to chicken korma, vegetable pulao, Mughlai parathas, beef kebabs, a rich raita with mint and dill, and for dessert, a choice between traditional rashmalai and kheer. (Zaman, 2018, p. 184)

The spread is "shamefully decadent" and Truman is quick to explain that the leftovers are never wasted and thrown away but sent to an orphanage, "that my cook used to volunteer for, after his services to the royal family" thereby making an effort to stabilize his position, as a representative of the American government, who were not to be identified with "war profiteers". (Zaman, 2018, p. 184)

The sinfully rich and decadent dishes that featured regularly on Sam Truman's menu are in glaring juxtaposition to that of Khoka, Ranjan, Mitali, Samina and Rounak's. These are men and women, who are not part of the Mukti Bahini, but have taken up arms against the forces that have not only occupied their home, but also branded their nationalist call as illegitimate. When the company visits the Chowdhury villa to meet and discuss matters with their mentor, Aisha, they are satisfied with the morsels that Mokaddas begrudgingly parts with. When they were on their own, their spread included "days-old leftovers, rice, dried fish, lentils". (Zaman, 2018, p. 293) The meal that they sit down to is neither nutritious, nor rich, nor appetizing, but rather the rice strewn with stones too many, which cannot be picked out, which "tortured their molars with a vicious quaking jolt", the "fish had bugs" and the "water in the lentils was pestilential”. (Zaman, 2018, p. 293)

Each of them devoured the food just to fill their stomach and give it some respite, the hunger pangs silenced, so they could plan their execution, as they were the "constant phantom of Mukti killers" stalking their prey. (Zaman, 2018, p. 278) These were revolutionaries whose 'Madhu Canteen' the shelter, the kitchen that not only doled out food to the hungry university students but also doubled as their landmark for gatherings when on campus, to discuss political scenarios and critique strategies. It was their perpetual hunger, their loss of the beloved Madhu Canteen which was razed to rubble and the death of their mates on campus which had turned them into these phantom creatures, who did not starve for food, but for independence.

\section{Conclusion}

In a review of the four distinct passages from Nadeem Zaman's In The Time of the Others, set against the backdrop of the Bangladesh Liberation War, the paper addresses the fact that the culinary register and its role in the state politics had remained unexplored and 'forgotten' as a cultural practice. The recovery is orchestrated through this paper and the two distinct sections that address two different angles to the domain of the 'culinary nationalism'. Priscilla Parkhurst Ferguson in the article 'Culinary Nationalism' writes of an occasion in the West where "cuisine 
and nation are seen to coincide" (Ferguson, 2010, p. 102) and this too can stand true for the discourse on South Asia, and a historically turbulent period in its past, where as Ferguson points out: "The recourse to tradition, to cultural values, to culinary practices and political principles of the past, responded to pervasive worries of loss of identity". (Ferguson, 2010, p. 104) The table that is set for Sam Truman indeed takes recourse to tradition and is gentle reminder of the nation's greatness, but this serves not only as a marker of the nation's heritage, its rich and diverse cuisine but also as a marker for the disparity as the nation struggles to feed nutritious food to its 'protectors' whereas it spreads a lavish banquet in front of its enemy collaborators. Ferguson further contends: "That culinary country is not to be found in the extravagant creations of celebrated (male) chefs in fancy modern restaurants but rather in the unpretentious, familiar dishes made every day in ordinary kitchens by everyday cooks". (Ferguson, 2010, p. 102) And the 'culinary country' that Nadeem Zaman celebrates, poised at the verge of war and peace, is a country with diverse practices and tastes and eating habits, all united in the fact that the culinary register speaks of not the personal but the political.

In the Introduction to Theory and Practice in Heritage and Sustainability: Between past and future, the editors introduce heritage as "often perceived simplistically as "protecting the past', or even 'saving' or 'rescuing' it, is in fact as complex and elusive to define as are the words 'culture' and 'sustainability"'. (Auclair \& Fairclough, 2015, p. 3) Zaman's narrativising of the fictional events in the history of the nation renders meaning to apparently innocent culinary registers. The state politics, the war and the armed resistance have been in scholarship the canonical domains of study, as Assmann defines the canon, vis-à-vis the analogy of the "prestigious objects" in the museum that are destined to "make a lasting impression" (Assmann, 2008, p. 99). The culinary register in this narrative is like the "other paintings and objects in peripheral spaces" in the museum, "not publicly presented", but these are a part of the "storehouse for cultural relicts" the borders of fiction. (Assmann, 2008, p. 99) Zaman's text in the context of the culinary registers "are open to new contexts and lend themselves to new interpretations" (Assmann, 2008, p. 99) thereby contributing to the 'culinary nationalism'.

The plurality in the culinary space which had remained in the "passive dimension of cultural memory" is in the words of Aleida Assmann "stored" and "potentially available" in the range of literature that exists on the eastern borders of the Partition and the Bangladesh Liberation War, for the "academic researcher or the artist to examine the contents of the archive and to reclaim the information by framing it within a new context". (Assmann, 2008, p. 103)

\section{Reference}

Assmann, A. (2008). Canon and Archive. In A. Erll, \& A. Nünning (Eds.), Cultural Memory Studies: An International and Interdisciplinary Handbook. Walter de Gruyter GmbH \& Co.

Auclair, E., \& Fairclough, G. (2015). Living between past and future: An Introduction to heritage and cultural sustainability. In Theory and Practice in Heritage and Sustainability: Between past and future. Routledge.

Das, C. (2017). In the Land of Buried Tongues: Testimonies and Literary Narratives of the War of Liberation of Bangladesh. Oxford University Press.

Das, T. K., Bhattacharyya, R., \& Sarma, P. K. (2020). Revisiting geographies of nationalism and national identity in Bangladesh. Geo Journal. https://doi.org/10.1007/s10708-02010305-1

Ferguson, P. P. (2010). Culinary Nationalism. Gastronomica: The Journal of Food and Culture, 10(1), 102-109. https://www.jstor.org/stable/10.1525/gfc.2010.10.1.102

Harrington, L. (2016). Crossing Borders in Partition Studies and the Question of the Bangladesh Liberation War. Postcolonial Text, 11(2), 1-16. https://eprints.soas.ac.uk/22739/1/2003-9676-1-PB.pdf 
Mookherjee, N. (2008). Culinary Boundaries and the Making of Place in Bangladesh. South Asia: Journal of South Asian Studies, 31(1), 56-75. doi:http://dx.doi.org/10.1080/00856400701874718

Murshid, N. (2011). India's Role in Bangladesh's War of Independence: Humanitarianism or Self-interest? Economic and Political Weekly, 46(52), 53-60. https://www.jstor.org/stable/41719989

Nimni, I. J., \& Khanom, M. (2016). Experience vs Experiment: The Portrayal of the Liberation War of Bangladesh in Rifle Roti Aurat and A Golden Age. Research Journal of English Language and Literature, 4(4), 266-274.

Parvin, S. (2015). War Mothers in a Non-Fiction and Two Fictional Works on the Liberation War of Bangladesh. Bangladesh Research Foundation Journal, 4(2), 113-119.

Ranjan, A. (2016). Bangladesh Liberation War of 1971: Narratives, Impacts and the Actors. India Quarterly: A Journal of International Affairs. https://doi.org/10.1177\%2F0974928416637921

Raychaudhury, A. B. (2004). Nostalgia of 'Desh', Memories of Partition. Economic and Political Weekly, 39(52), 5653-5660. http://www.jstor.org/stable/4415984

Roy, R. (2009). The Hungry Tide: Bengali Hindu Refugees in the Subcontinent. The Newsletter (51). https://www.iias.asia/sites/default/files/nwl_article/201905/IIAS_NL51_0809.pdf

Schendel, W. V. (2001). Working through Partition: Making a Living in the Bengal Borderlands. IRSH, 46, 393-421. doi:10.1017/S0020859001000256

Shamsie, K. (2002). Kartography. Bloomsbury.

Zaman, N. (2018). In The Time of the Others. Picador India.

\section{$\underline{\text { Bio-note }}$}

Namrata Chowdhury is a PhD scholar at West Bengal State University, and an Assistant Professor at St. Xavier's College (Autonomous), Kolkata.

Email Id: nc20391@gmail.com 